\title{
FATORES CRÍTICOS DE SUCESSO NA IMPLEMENTAÇÃO DO PROGRAMA SEIS SIGMA: UMA REVISÃO SISTEMÁTICA DAS PESQUISAS QUANTITATIVAS
}

\section{CRITICAL SUCCESS FACTORS IN THE IMPLEMENTATION OF SIX SIGMA PROGRAM: A SYSTEMATIC REVIEW OF QUANTITATIVE RESEARCH}

\author{
Daniela Santana Lambert Marzagão* E-mail: daniela.marzagao@gpsqtc.com.br \\ Ana Paula Vilas Boas Viveiros Lopes* E-mail: paulavlopes@usp.br \\ Maria Aparecida Gouvêa*E-mail: mgouvea@usp.br \\ Marly Monteiro de Carvalho*E-mail: marlymc@usp.br \\ *Universidade de São Paulo (USP), São Paulo, SP
}

\begin{abstract}
Resumo: O objetivo desse trabalho é revisar a bibliografia sobre Seis Sigma, identificando fatores críticos de sucesso. Para isso, os autores construíram uma fundamentação teórica para auxiliar as análises estatísticas. Buscaram artigos na base ISI Web of Knowledge, através das palavras chaves "Six Sigma" e "Quality", no período entre 1988 e 2010. Dos 270 trabalhos gerados na busca, 11 abordavam uma pesquisa tipo Survey com similaridade de assuntos. A meta análise foi feita em 6 destes 11 artigos, os quais estavam disponíveis sem custo. Os resultados mostraram que poucos estudos quantitativos foram realizados. Do ponto de vista estatístico, as principais limitações foram o tamanho das amostras e a escolha de ferramentas adequadas. Os quatro fatores críticos de sucesso que puderam ser comparados foram: cultura da qualidade, envolvimento dos funcionários, seleção de projetos e treinamento e aprendizado. Um diferencial encontrado entre Seis Sigma e outras iniciativas de qualidade é a integração com a Gestão de Portfólio.
\end{abstract}

Palavras-chaves: Métodos multivariados. Revisão sistemática. Fatores críticos de sucesso. Seis sigma. Qualidade.

\begin{abstract}
The aim of this paper is to review the literature on Six Sigma, identifying critical success factors. For this, the authors developed a theoretical framework to assist the statistical analysis. We searched articles in ISI Web of Knowledge, using the words "Six Sigma" and "Quality" in the period between 1988 and 2010. Of the 270 jobs generated in the search, type a search addressed 11 Survey with similarity of issues. A meta-analysis was performed in 6 of these 11 articles, which were available at no cost. The results showed that very few quantitative studies were performed. From a statistical viewpoint, the main limitations were the sample size and choice of appropriate tools. The four critical success factors that could be compared were: quality culture, employee involvement, project selection and training and learning. A difference found between Six Sigma and other quality initiatives is the integration with the Portfolio Management.
\end{abstract}

Keywords: Multivariate Methods. Systematic Review. Critical Success Factors. Six Sigma. Quality.

\section{INTRODUÇÃO}

A partir da década de 90, muitas empresas passaram a adotar o Seis Sigma como um programa de qualidade que pode proporcionar benefícios financeiros e estratégicos tangíveis de uma maneira rápida. 
Para Harry \& Linsenmann (2006), "Seis Sigma é uma estratégia que se apóia em sua capacidade de cumprir suas metas". Estes autores também mencionam que o Seis Sigma é uma iniciativa estratégica que pode ser considerada um veículo para as demais iniciativas estratégicas.

Já Schroeder et al. (2007), definem Seis Sigma como "uma meso-estrutura paralela, organizada para reduzir a variação de processos utilizando-se de especialistas em melhoria, um método estruturado e métricas de desempenho com a meta de atingir objetivos estratégicos". Eles também sugerem que Seis Sigma seja visto como um processo de mudança organizacional.

Carvalho et al. (2007) relatam o aumento na adoção do Seis Sigma por empresas no Brasil, em especial a partir de 2004. Porém, chama a atenção nesse estudo que os autores não encontram uma correlação positiva entre investimentos realizados e resultados obtidos a partir da implantação do Seis Sigma.

Muitas empresas, baseadas no sucesso das organizações pioneiras, buscaram a implementação dos Projetos Seis Sigma e seus resultados nem sempre atenderam esta expectativa.

A partir desta lacuna buscou-se fazer uma revisão da bibliografia sobre Seis Sigma, a qual mostra que existem itens que podem influenciar o sucesso da implementação, sendo que existe um universo de autores que trata de forma quantitativa a relação entre estes fatores e o desempenho do programa.

Posto este cenário, este estudo visa revisar as análises quantitativas dos fatores críticos de sucesso de tal maneira a avaliar os resultados de maneira sistemática, realizando uma análise crítica dos métodos utilizados e trabalhando o conjunto dos resultados pelo método da meta análise, reduzindo os vieses de tamanho de amostra e regionalidade dos estudos no intuito de obter uma visão mais abrangente dos fatores que podem interferir no sucesso do Seis Sigma dentro das organizações.

Para atingir este objetivo, este artigo está estruturado em uma revisão bibliográfica que inclui a literatura de Seis Sigma e a literatura de métodos estatísticos de análise de dados. Em seguida, este artigo trata da metodologia utilizada no trabalho, passando à descrição dos resultados obtidos, análise e discussão dos resultados e finalmente às conclusões. 


\section{FUNDAMENTAÇÃO TEÓRICA}

\subsection{Seis Sigma}

Para caracterizar o Seis Sigma e os fatores presentes nesse estudo, foram levantadas algumas definições iniciais, um panorama geral e em seguida, um recorte mais específico sobre a literatura de fatores críticos de sucesso.

Muitos autores discutem se o Seis Sigma pode ou não ser considerado uma forma de gestão da qualidade diferente do TQM (ZU et al., 2008; KAYNAK, 2003; KWAK \& ANBARI, 2006; YEUNG et al., 2006; SCHROEDER et al., 2007).

Embora Kaynak (2003) defenda que o Seis Sigma pode ser considerado "TQM com esteróides", Zu et al. (2008) e Schroeder et al. (2007) identificam que o Seis Sigma utiliza uma plataforma comum de conhecimentos, práticas e recursos da qualidade, complementando-os com algumas características e recursos específicos a fim de aumentar sua efetividade.

Para Lindermann et al. (2003, p.195) "Seis Sigma é um método organizado e sistemático para a melhoria de processos e do desenvolvimento de novos produtos e serviços, baseado em técnicas estatísticas e científicas, com o objetivo de reduzir defeitos definidos pelos clientes".

Rotondaro et al. (2002, p18) afirmam que "Seis Sigma é uma filosofia de trabalho para alcançar, maximizar e manter o sucesso comercial, por meio da compreensão das necessidades do cliente".

Segundo Harry \& Schroeder (2000), a seleção dos projetos Seis Sigma deve ser "identificada nos objetivos e direcionamentos estratégicos da empresa". A "necessidade de selecionar, aplicar e adaptar métodos e idéias Seis Sigma para que se encaixem nas necessidades e prontidão de sua empresa" (PANDE et al., 2001) indica que existe uma flexibilidade na aplicação de Projetos Seis Sigma.

Quando um novo processo é requerido, o Design For Six Sigma (DFSS) é utilizado. O DFSS consiste de um número de disciplinadas e rigorosas abordagens para produtos, processos e desenvolvimento de serviços (EL-HAIK \& ROY, 2005).

Segundo Yang (2005), DFSS é "uma metodologia sistemática que usa ferramentas, treinamento, gestão de projetos e disciplina para aperfeiçoar o 
processo de desenvolvimento de produtos" e guia o processo de desenvolvimento prevenindo problemas, usando um roteiro que foca a prevenção de defeitos e a criação de valor.

Pande et al. (2000) tratam do histórico e dos princípios da implantação do Seis Sigma nas grandes indústrias, notoriamente nas empresas Motorola e General Electric. Já Breyfogle (1999) provê uma rotina e um conjunto de ferramentas que envolvem as fases de definição, medição, análise, melhoria e controle para a implementação passo-a-passo de um projeto Seis Sigma. Hoerl (1998) trata o Seis Sigma como uma evolução estratégica do papel da qualidade das empresas e descreve um roteiro de implementação. Todos estes autores acreditam na necessidade do Seis Sigma estar apoiado pela alta liderança da empresa e alinhado aos objetivos estratégicos. Outra referência importante é Linderman et al. (2003), que definem o sucesso do Seis Sigma sob a perspectiva do efeito da cobrança de metas na formação das equipes e seu desempenho.

Hackman \& Wageman (1995) discutem o papel da Gestão da Qualidade e propõem uma abordagem mais focada em resultados, atribuindo ao Seis Sigma este papel. O livro de Harry \& Schroeder (2000) prescreve uma forma executiva de implementação do Seis Sigma, de tal forma a replicar os resultados obtidos em outras empresas, semelhante ao artigo de Henderson \& Evans (2000), que apresenta o benchmark da implementação do Seis Sigma na empresa General Electric, evidenciando o alinhamento destas implementações com as necessidades estratégicas das empresas citadas.

Hoerl (2001) debate que a principal razão que faz do Seis Sigma uma iniciativa de melhoria e não apenas um grupo de ferramentas estatísticas é o papel essencial do Black Belt na estratégia global de implementação. Hahn et al. (1999) indicaram a importância da aplicação do Seis Sigma por profissionais, ao invés de estatísticos, considerando a estratégia e as principais necessidades das empresas.

\subsection{Fatores Críticos de Sucesso nos Projetos Seis Sigma}

Considerando agora uma visão mais específica dos fatores que levam ao sucesso ou ao fracasso das iniciativas do Seis Sigma dentro das organizações, 
podemos destacar o trabalho de Coronado \& Antony (2002) na identificação de fatores críticos de sucesso na implementação de projetos Seis Sigma, tais como compromisso e envolvimento da alta gerência, cultura, comunicação, treinamento e a ligação direta do Seis Sigma com a estratégia da empresa, com os clientes, recursos humanos e fornecedores.

Goh (2002), por sua vez, faz uma análise crítica do ponto de vista estratégico, considerando os efetivos benefícios do Programa Seis Sigma nas empresas, como por exemplo, a obtenção de hierarquia de execução e metas claras de desempenho, implantação estruturada de ferramentas DMAIC e decisões baseadas em fatos. O livro de Pyzdek (2003) constitui um roteiro de implementação prescrevendo aos líderes de projeto seus próximos passos na implantação exitosa do programa.

Além destes, também referenciam os artigos mais citados as obras de Antony \& Bañuelas (2002), que fazem um estudo das técnicas e ferramentas mais utilizadas em projetos Seis Sigma de sucesso; Kwak \& Anbari (2006) que fazem uma revisão de literatura discutindo as características dos projetos de melhoria (DMAIC) e de desenvolvimento (DFSS), o histórico de implementação e os fatores críticos de sucesso no Programa Seis Sigma, na mesma linha do trabalho de Raisinghani et al. (2005); Snee \& Rodebaugh (2002) discutem o processo de seleção de projetos Seis Sigma e os critérios para a formação do portfólio de projetos.

Considerando a literatura de fatores críticos de sucesso do Seis Sigma, Cheng (2009) menciona o alinhamento dos projetos com a estratégia, cultura organizacional voltada para qualidade, diagnóstico da gestão da qualidade, estratégia de gestão da qualidade, uso de projetos com o método DMAIC, criação dos papéis de Champion, Master Black Belt, Black Belt e Green Belt e sistema de comunicação das atividades de qualidade como os fatores que levam ao êxito na implementação do programa.

Kumar \& Antony (2008) mencionam o envolvimento e o comprometimento da liderança, comunicação, ligação da qualidade com o empregado, mudança cultural, educação e treinamento, ligação da qualidade com o cliente, seleção de projetos, ligação da qualidade com o negócio, ligação da qualidade com os fornecedores, habilidade em gestão de projetos, infra-estrutura organizacional, visão e 
planejamento, TI e inovação como itens críticos no desempenho dos Projetos Seis Sigma.

Já Van Iwaarden et al. (2008) mencionam resultados positivos dos projetos Seis Sigma, continuidade do apoio da liderança, envolvimento dos donos de processo na seleção dos projetos, efetiva e frequente comunicação do progresso do Seis Sigma, encorajamento do uso das ferramentas aprendidas em ações de melhoria, registro dos ganhos financeiros, asseguramento que as necessidades dos clientes internos e externos foram atendidas, ligar o Seis Sigma com outras iniciativas de qualidade, integrar o Seis Sigma no sistema de gestão da qualidade, estabilidade nas posições de alta liderança, desempenho positivo do negócio, aumento da competição no mercado, aumento das ferramentas e técnicas utilizadas pelo Seis Sigma, pressão do mercado for preço como fatores que afetam os resultados dos Projetos Seis Sigma.

\subsection{Coleta e análise de dados}

A realidade atual exige que empresas sejam cada vez mais lucrativas, com custos reduzidos, maior flexibilidade, rapidez e qualidade de serviços e produtos.

Segundo Hair et al. (2009), o acúmulo crescente de dados exige que estas informações sejam coletas, armazenadas e analisadas criteriosamente, de forma a auxiliarem as tomadas de decisão e consequentemente, obtenção de melhores resultados.

A análise multivariada é uma forma de análise estatística de dados e pode ser definida de maneiras distintas pelos pesquisadores. Alguns a utilizam apenas para analisar a relação entre mais de duas variáveis. Outros assumem que todas as variáveis possuem distribuição normal. Porém, "para uma análise ser considerada verdadeiramente multivariada, todas as variáveis estatísticas devem ser aleatórias e inter-relacionadas de tal maneira que seus efeitos não podem ser significativamente interpretados em separado" (HAIR et al., 2009).

O Quadro 1 mostra de forma resumida, as escalas de medidas das variáveis. 
Quadro 1 - Escalas de medida

\begin{tabular}{|c|c|c|c|}
\hline \multirow{4}{*}{ Escalas não métricas } & \multirow[t]{2}{*}{ Nominal } & Definição & $\begin{array}{l}\text { envolve o ato de nomear, rotular ou classificar um objeto, pessoa } \\
\text { ou alguma característica, por meio de números, os quais têm } \\
\text { função puramente de classificação, não podendo ser operados } \\
\text { aritmeticamente }\end{array}$ \\
\hline & & Exemplo & sexo: 1 - homem; 2 - mulher \\
\hline & \multirow[t]{2}{*}{ Ordinal } & Definição & $\begin{array}{l}\text { a variável possui categorias que mantém uma relação de ordem } \\
\text { do menor para o maior. Os valores das categorias indicam uma } \\
\text { hierarquização }\end{array}$ \\
\hline & & Exemplo & níveis de satisfação: do muito insatisfeito ao muito satisfeito \\
\hline \multirow{4}{*}{ Escalas métricas } & \multirow[t]{2}{*}{ Intervalar } & Definição & $\begin{array}{l}\text { a variável possui categorias que mantém uma relação de ordem } \\
\text { e intervalos iguais de medição. O zero não é absoluto, pois é } \\
\text { arbitrário, não sendo possível estabelecer comparações do tipo } \\
\text { fracionário entre as categorias }\end{array}$ \\
\hline & & Exemplo & $80^{\circ} \mathrm{F}$ não é o dobro de $40^{\circ} \mathrm{F}$ \\
\hline & \multirow[t]{2}{*}{ Razão } & Definição & $\begin{array}{l}\text { além das características do nível intervalar, o zero é absoluto, } \\
\text { indicando que há m ponto na escala onde não existe a } \\
\text { propriedade inerente á variável. Ė possível comparar as } \\
\text { categorias da variável em termos fracionários }\end{array}$ \\
\hline & & Exemplo & idade, renda \\
\hline
\end{tabular}

Fonte: Adaptado de Martins \& Theóphilo (2007).

\subsubsection{Survey}

Segundo Filippini (1997), o termo Survey pode ser aplicado a coletas de dados, informações ou opiniões de uma grande quantidade de unidades de análise, que podem ser indivíduos, grupos e empresas, utilizando questionários estruturados e pré-definidos.

As análises tipo Survey são consideradas exploratórias quando visam determinar quais conceitos estão relacionados a um determinado fenômeno, permitindo a formação de uma base para um estudo mais aprofundado, sendo em geral conduzido em etapas iniciais do estudo (FILIPPINI, 1997; FORZA, 2002).

Forza (2002) propõe que os estudos do tipo Survey sejam conduzidos obedecendo-se um processo que contempla as etapas descritas na Figura 1. 
Figura 1 - Esquema de pesquisa tipo Survey

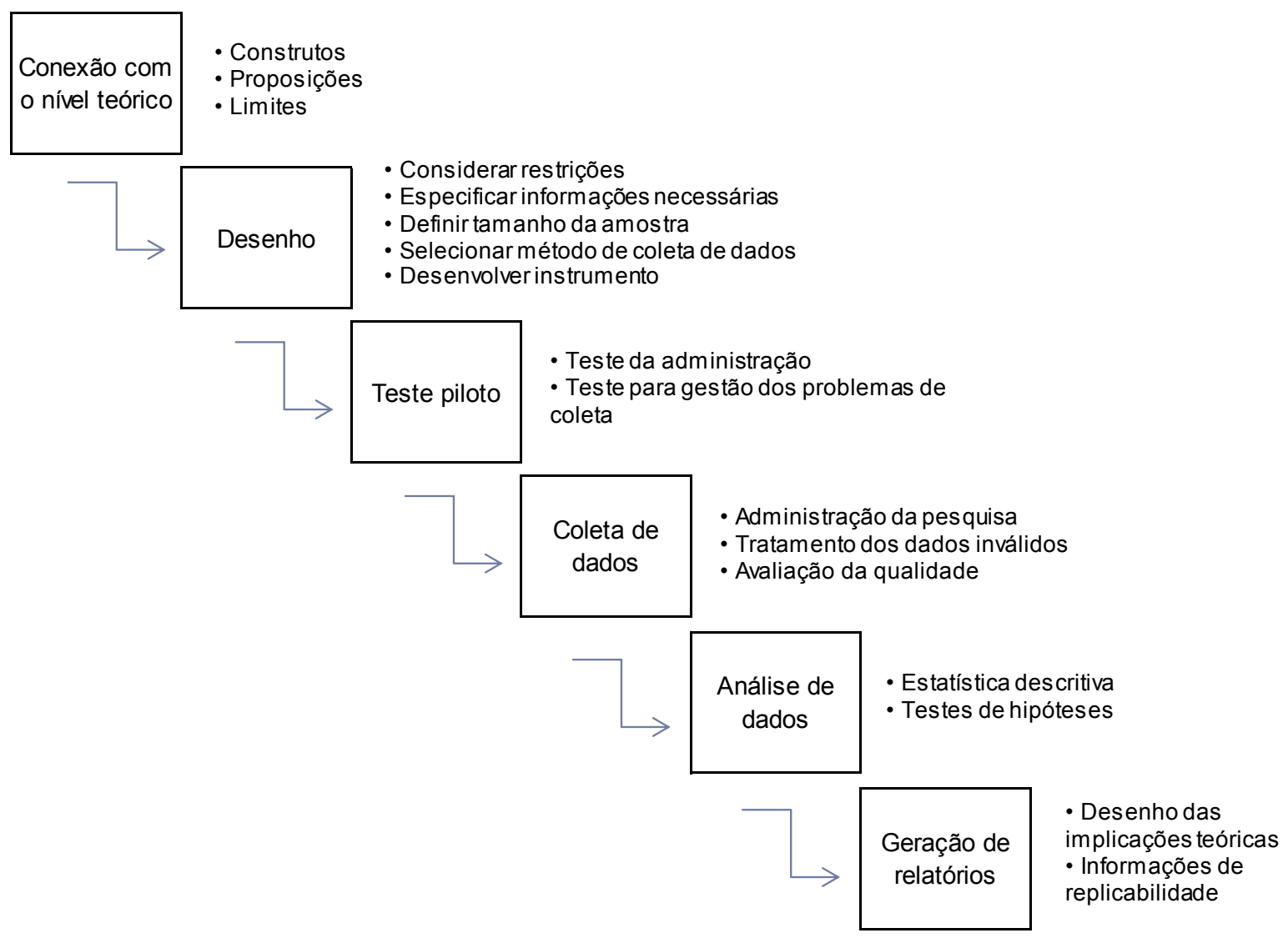

Fonte: Adaptado de Forza (2002)

$\mathrm{Na}$ etapa de análise de dados costuma-se também separar as estatísticas em duas categorias: descritiva e inferencial. Ambas as categorias oferecem técnicas uni, bi e multivariadas.

$\mathrm{Na}$ geração de relatórios pode-se também incluir limitações do trabalho e sugestões de estudos futuros.

Ao tratar de um conjunto composto de uma variável independente relacionando-se a uma variável dependente, temos o que é chamado de análise univariada. No caso de haver mais de uma variável independente ou dependente e de haver a necessidade de testar a relação interna entre elas, temos uma análise que pode ser descrita como multivariada. (HAIR et al., 1995). 
Segundo Atallah \& Castro (2010), a “a revisão sistemática é uma revisão planejada para responder a uma pergunta específica e que utiliza métodos explícitos e sistemáticos para identificar, selecionar e avaliar criticamente os estudos, e para coletar e analisar os dados destes estudos incluídos na revisão".

A meta análise, ainda segundo estes autores, "é o método estatístico utilizado na revisão sistemática para integrar os resultados dos estudos incluídos".

A Colaboração Cochrane apud Atallah \& Castro (2010) sugere que a revisão sistemática seja realizada através dos passos mostrados na Figura 2.

Figura 2 - Esquema de análise sistemática

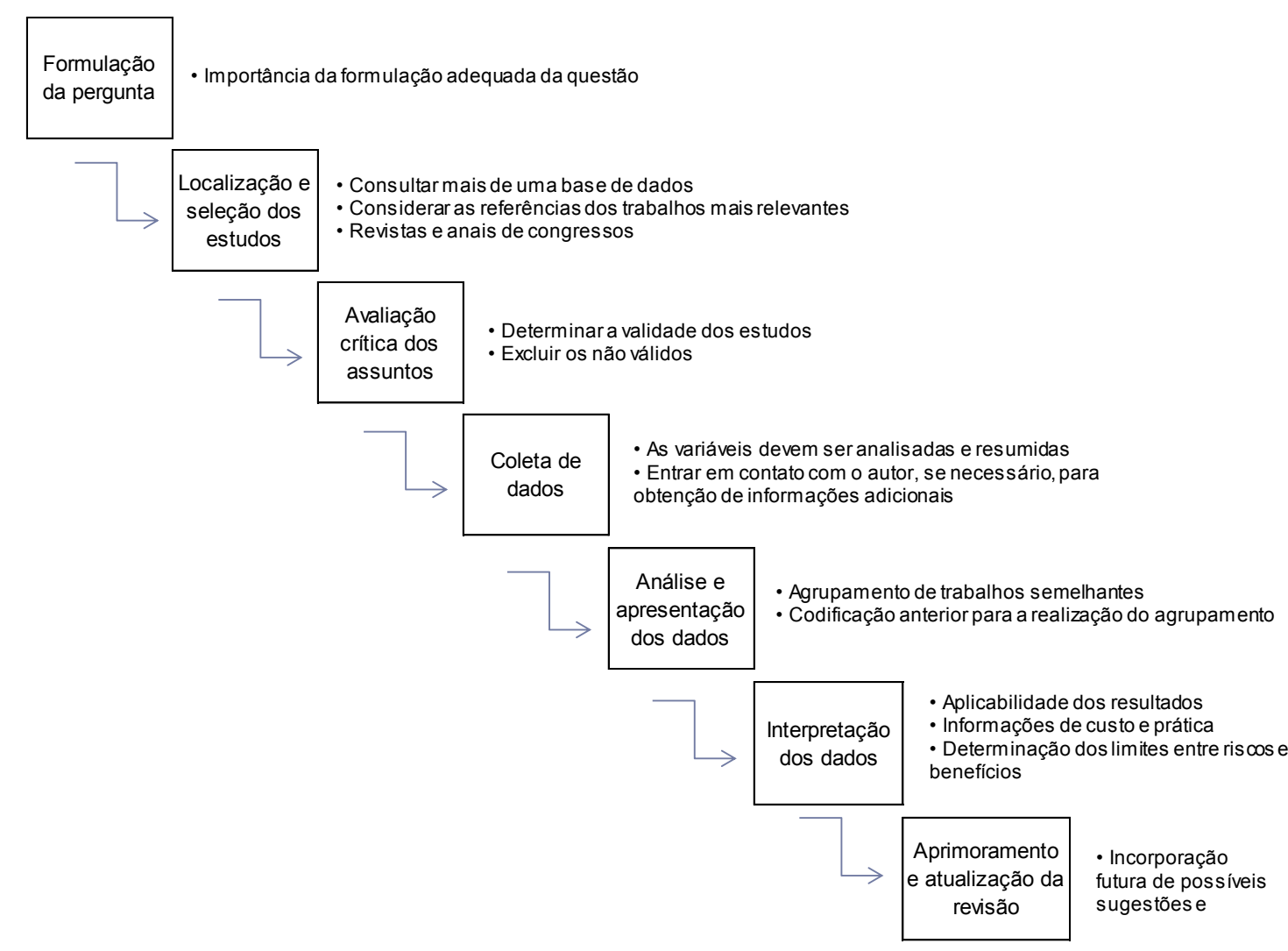

Fonte: Adaptado de Atallah \& Castro (2010)

A Figura 3 mostra possíveis resultados de uma revisão sistemática. 
Figura 3 - Possíveis resultados

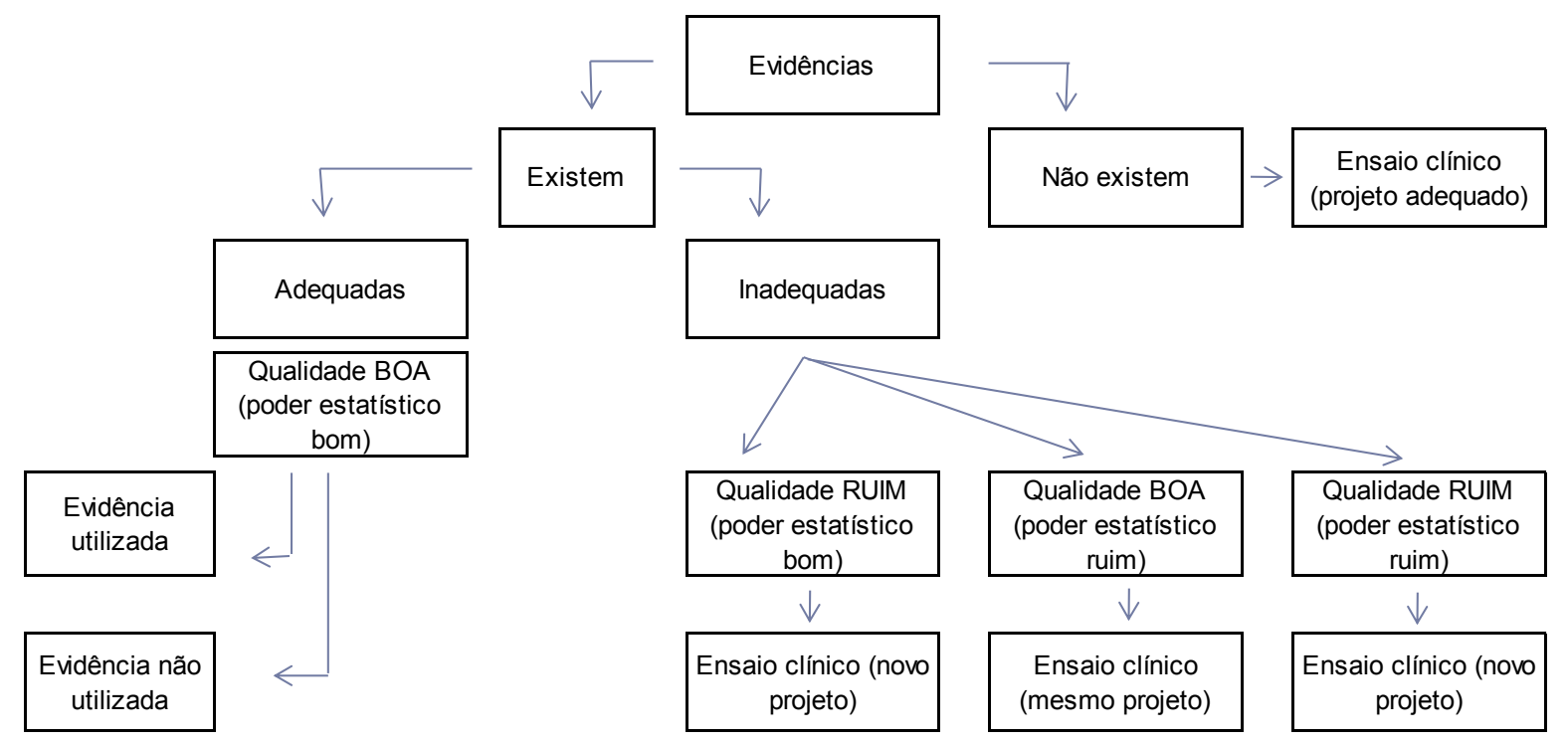

Fonte: Adaptado de Atallah \& Castro (2010)

Nota-se que na presença de evidências adequadas (seleção adequada de estudos) e bons resultados estatísticos, as mesmas poderão ou não ser utilizadas de acordo com a necessidade. Já na presença de evidências inadequadas podemos ter:

- Qualidade ruim e poder estatístico bom: uma intervenção é superior à outra e a meta análise é importante para o cálculo do tamanho da amostra de estudos futuros.

- Qualidade boa e poder estatístico ruim: não existe uma intervenção superior à outra e os dados estatísticos só servem de base para estudos futuros.

- Qualidade ruim e poder estatístico ruim: não existe uma intervenção superior à outra e os dados estatísticos só servem de base para estudos futuros.

\subsubsection{Técnicas de análise multivariada}

\subsubsection{Análise discriminante}

O Quadro 2 resume as principais características da técnica. 
Quadro 2 - Características da técnica de análise discriminante

\begin{tabular}{|c|c|}
\hline \multicolumn{2}{|r|}{ ANÁLISE DISCRIMINANTE } \\
\hline Definição & $\begin{array}{l}\text { Técnica que envolve uma relação de dependência entre variáveis. Produz } \\
\text { combinações lineares das variáveis independentes (função discriminante) que } \\
\text { melhor discriminam os grupos estabelecidos pela variável dependente }\end{array}$ \\
\hline Parâmetros & $\begin{array}{l}\text { Maximização da razão entre variância entre os grupos e a variância dentro dos } \\
\text { grupos }\end{array}$ \\
\hline Exemplo & $\begin{array}{l}\text { Quero prever se uma empresa irá ou não (sim ou não - variável categórica de } \\
\text { resposta) entrar no ranking de reclamações no Procon, utilizando os dados de } \\
\text { valor de investimento em qualidade ( } R \text { - escala razão), valor do investimento } \\
\text { em atendimento ao cliente ( } R \$ \text { - escala razão) e número total de clientes } \\
\text { atendidos no ano (Quantidade - escala razão) }\end{array}$ \\
\hline Variáveis de entrada & Duas ou mais variáveis independentes do tipo razão ou intervalar \\
\hline Variáveis de saída & Uma variável dependente do tipo categórica de dois ou mais níveis \\
\hline $\begin{array}{l}\text { Relação entre } \\
\text { premissas e } \\
\text { respectivos testes }\end{array}$ & $\begin{array}{l}\text { Normalidade das variáveis independentes: teste de Kolmogorov Smirnov para } \\
\text { cada variável separadamente } \\
\text { Linearidade das relações: avaliação gráfica e correlações entre as variáveis } \\
\text { independentes } \\
\text { Sem problemas de multicolinearidade: uso do método stepwise para não } \\
\text { serem incluídas variáveis excessivamente correlacionadas } \\
\text { Variâncias iguais nos grupos: realização do teste Box's M } \\
\text { Sem outliers: análise prévia com cada variável independente elaborando-se o } \\
\text { gráfico Box-plot e/ou análise simultânea das variáveis independentes com o } \\
\text { cálculo da estatística distância de Mahalanobis }\end{array}$ \\
\hline
\end{tabular}

Fonte: Adaptado de Hair Jr. et al. (2009)

Tem como objetivo "obter uma função discriminatória por meio de combinações lineares das variáveis independentes, a partir da qual seja possível classificar os elementos em cada uma das categorias da variável dependente" (GOUVÊA, 2010).

Segundo Tabachnick \& Fidell (1996), a meta da análise discriminante é predizer membros de um grupo.

\subsubsection{Regressão Logística}

O quadro 3 resume as principais características da técnica. 
Quadro 3 - Características da técnica de regressão logística.

\begin{tabular}{|c|c|}
\hline \multicolumn{2}{|r|}{ REGRESSÃO LOGÍSTICA } \\
\hline Definição & $\begin{array}{l}\text { Técnica utilizada para aferição de probabilidade de ocorrência de um evento e } \\
\text { para identificação das características dos elementos pertencentes a cada } \\
\text { categoria estabelecida pela dicotomia da variável dependente (variável grupo) }\end{array}$ \\
\hline Exemplo & $\begin{array}{l}\text { Quero prever se um cliente de uma seguradora irá ou não bater o carro (sim ou } \\
\text { não - variável categórica binária) em função de sua idade (variável métrica), } \\
\text { seu sexo (variável categórica), o número de km percorridos por dia (variável } \\
\text { métrica) e a cidade onde habita (variável categórica) }\end{array}$ \\
\hline Variáveis de entrada & $\begin{array}{l}\text { Duas ou mais variáveis independentes métricas ou não métricas (razão, } \\
\text { intervalar, categórica usando dummy, etc) }\end{array}$ \\
\hline Variáveis de saída & Uma variável dependente categórica \\
\hline $\begin{array}{c}\text { Relação entre } \\
\text { premissas e } \\
\text { respectivos testes }\end{array}$ & $\begin{array}{l}\text { Normalidade das variáveis independentes: teste de Kolmogorov Smirnov para } \\
\text { cada variável separadamente; a técnica é robusta caso esta condição não seja } \\
\text { satisfeita } \\
\text { Sem outliers: análise prévia com cada variável independente elaborando-se o } \\
\text { gráfico Box-plot e/ou análise simultânea das variáveis independentes com o } \\
\text { cálculo da estatística distância de Mahalanobis }\end{array}$ \\
\hline
\end{tabular}

Fonte: Adaptado de Hair Jr. et al. (2009)

Utilizando uma série de variáveis independentes, tem como objetivo estabelecer uma função para prever a separação clara entre os elementos da amostra em dois grupos de uma variável dependente.

\subsubsection{Correlação canônica}

O quadro 4 resume as principais características da técnica. 
Quadro 4 - Características da técnica de correlação canônica

\begin{tabular}{|c|c|}
\hline \multicolumn{2}{|r|}{ CORRELAÇÃO CANÔNICA } \\
\hline Definição & $\begin{array}{l}\text { Técnica que facilita o estudo das inter-relações entre conjuntos de variáveis } \\
\text { dependentes múltiplas e independentes múltiplas }\end{array}$ \\
\hline Exemplo & $\begin{array}{l}\text { Quero prever a renda (variavel dependente - escala razão) e o patrimônio } \\
\text { (variavel dependente - escala razão) de um grupo de pessoas em função do } \\
\text { número de anos de educação (variavel independente - escala razão) e da } \\
\text { idade (variavel independente - escala razão) }\end{array}$ \\
\hline Variáveis de entrada & Duas ou mais variáveis independentes do tipo razão \\
\hline Variáveis de saída & Duas ou mais variáveis dependentes do tipo razão \\
\hline $\begin{array}{l}\text { Relação entre } \\
\text { premissas e } \\
\text { respectivos testes }\end{array}$ & $\begin{array}{l}\text { Linearidade das relações: avaliação gráfica e correlações entre as variáveis } \\
\text { dependentes e independentes } \\
\text { Normalidade das variáveis dependentes e independentes: teste de Kolmogorov } \\
\text { Smirnov para cada variável separadamente; é muito difíil atender a } \\
\text { normalidade multivariada e a técnica é robusta se a normalidade univariada for } \\
\text { satisfeita } \\
\text { Sem outliers: análise prévia com cada variável dependente e independente } \\
\text { elaborando-se o gráfico Box-plot e/ou análise simultânea das variáveis } \\
\text { dependentes e independentes com o cálculo da estatística distância de } \\
\text { Mahalanobis }\end{array}$ \\
\hline
\end{tabular}

Fonte: Adaptado de Hair Jr. et al. (2009)

Considerando um conjunto de variáveis dependentes e outro conjunto de variáveis independentes, tem como objetivo estabelecer funções que maximizam a variância de um conjunto que é compartilhada pelo outro conjunto.

\subsubsection{MANOVA}

O quadro 5 resume as principais características da técnica. 
Quadro 5 - Resumo da técnica de MANOVA

\begin{tabular}{|c|l|}
\hline \multicolumn{2}{|c|}{ MANOVA } \\
\hline Definição & $\begin{array}{l}\text { Técnica de dependência que compara as diferenças de média para duas ou } \\
\text { mais variáveis dependentes com base em um conjunto de variáveis } \\
\text { independentes. Extensão da análise univariada de variância (anova) com a } \\
\text { incorporação de mais uma variável dependente }\end{array}$ \\
\hline Exemplo & $\begin{array}{l}\text { Quero prever se o faturamento bruto (variável dependente - escala razão) e o } \\
\text { EBITDA (variável dependente - escala razão) de uma série de empresas de um } \\
\text { mesmo setor é diferente em função do tipo de estrutura adotado (variável } \\
\text { independente categórica), se a gestão financeira é centralizada ou não (variável } \\
\text { independente categórica) e se a empresa adota algum programa de redução } \\
\text { de custos (variável independente categórica) }\end{array}$ \\
\hline Variáveis de entrada & $\begin{array}{l}\text { Duas ou mais variáveis independentes do tipo categóricas ou categóricas + } \\
\text { razão }\end{array}$ \\
\hline Variáveis de saída & Duas ou mais variáveis dependentes do tipo razão (não aceita dummy) \\
\hline $\begin{array}{c}\text { Relação entre } \\
\text { premissas e } \\
\text { respectivos testes }\end{array}$ & $\begin{array}{l}\text { Linearidade das relações: avaliação gráfica e correlações entre as variáveis } \\
\text { dependentes } \\
\text { Sem problemas de multicolinearidade: teste de Bartlett e Roy Bargman } \\
\text { Variâncias iguais nos grupos: realização do teste Box's M }\end{array}$ \\
\hline
\end{tabular}

Fonte: Adaptado de Hair Jr. et al. (2009)

Utilizando uma série de variáveis independentes categóricas, tem como objetivo estabelecer se existe diferença entre as médias de um vetor de variáveis resposta em cada grupo, que representa uma determinada combinação dos níveis das variáveis de entrada. Verificar se os fatores ou uma combinação de fatores exercem influência significativa sobre as variáveis dependentes.

\subsubsection{Conjoint}

O quadro 6 resume as principais características da técnica. 
Quadro 6 - Resumo da técnica de Conjoint

\begin{tabular}{|c|l|}
\hline \multicolumn{2}{|c|}{ CONJOINT ANALYSIS } \\
\hline Definição & $\begin{array}{l}\text { Utilizando uma série de variáveis de entrada e uma variável de saída que pode } \\
\text { ser uma nota ou um ranking, estabelecer uma função de utilidade que revele a } \\
\text { preferência dos entrevistados }\end{array}$ \\
\hline Exemplo & $\begin{array}{l}\text { Quero saber qual o formato de uma loja vai fazer mais sucesso entre os } \\
\text { clientes, considerando notas (variável dependente razão) dadas pelos clientes } \\
\text { para as combinações entre local (variável categórica), faixas de distância do } \\
\text { centro da cidade (variável razão categorizada) e estilos de decoração da loja } \\
\text { (variável categórica) }\end{array}$ \\
\hline Variáveis de entrada & Duas ou mais variáveis independentes categóricas \\
\hline Variáveis de saída & Uma variável dependente razão \\
\hline $\begin{array}{c}\text { Testes para avaliar as } \\
\text { premissas }\end{array}$ & $\begin{array}{l}\text { Grupos balanceados: cada nível de cada categoria } \\
\text { Estímulos não óbvios: bom senso (Exemplo: uma Ferrari por US\$ 1000,00) } \\
\text { Estímulos viáveis: bom senso (Exemplo: uma propaganda com fundo e letras } \\
\text { em preto) } \\
\text { Estímulos ortogonais: as variáveis de entrada devem ser independentes } \\
\text { Classificação dos níveis dos estímulos: modelos discretos }\end{array}$ \\
\hline
\end{tabular}

Fonte: Adaptado de Hair Jr. et al. (2009)

Utilizando uma série de variáveis categóricas de entrada e uma variável de saída que pode ser uma nota ou um ranking, tem como objetivo estabelecer uma função de utilidade que revele a preferência dos entrevistados.

Foram selecionadas técnicas de dependência para serem analisadas neste trabalho, porém, optou-se por não pesquisar análise de regressão e modelagem de equações estruturais pela baixa incidência de utilização nos textos pesquisados.

\section{METODOLOGIA DE PESQUISA}

Segundo Atallah \& Castro (2010), a meta análise permite aos pesquisadores a montagem de um quebra-cabeça sobre uma temática desejada. Cada trabalho é uma peça, a qual pode aparecer mais de uma vez em uma pesquisa ou pode até mesmo não aparecer nenhuma vez. Através da meta análise os pesquisadores podem realizar adequadamente uma coleta, armazenamento e análise estatística de dados. 


\subsection{Coleta e seleção dos trabalhos}

Os autores realizaram a busca de trabalhos na base ISI Web of Knowledge através da combinação dos tópicos "Six Sigma" e "Quality". Os autores decidiram analisar apenas artigos.

A busca resultou em 270 trabalhos, entre 1988 e 2010, os quais foram tratados de acordo com o fluxo da Figura 4.

Figura 4 - Tratamento dos artigos

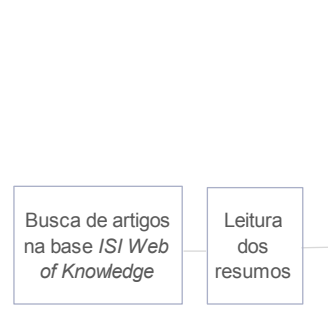

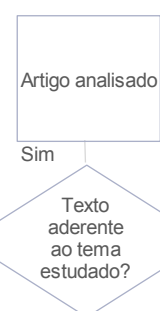

Não

Artigo excluido
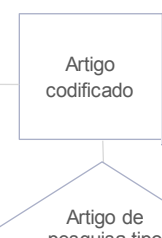

pesquisa tipo
Survey?

Não

Artigo excluido

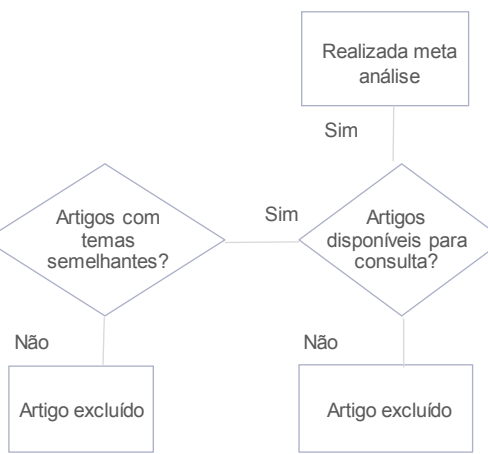

Após a leitura dos resumos, 38 artigos foram excluídos por não aderência ao tema Seis Sigma.

Os 232 artigos restantes foram codificados segundo o Quadro 7.

Quadro 7 - Tipologia de estudo

\begin{tabular}{|c|c|}
\cline { 2 - 2 } \multicolumn{1}{c|}{} & Tipo de estudo \\
\hline A & modelagem \\
\hline B & teórico-conceitual \\
\hline C & revisão de literatura \\
\hline D & simulação \\
\hline E & survey \\
\hline F & estudo de caso \\
\hline G & pesquisa-ação \\
\hline H & experimental \\
\hline
\end{tabular}


A codificação resultou em 38 artigos com pesquisa tipo $E=$ Survey, dos quais 11 tinham temas semelhantes e poderiam ser analisados através da meta análise. No entanto, somente 6 artigos estavam disponíveis para a leitura completa, requisito necessário para o tratamento que se buscava.

Estes 6 artigos foram lidos integralmente, buscando-se identificar: objetivo do artigo; variável moderadora; variáveis explanatórias; variáveis dependentes; respectivas escalas; técnica utilizada para análise.

\subsection{Aplicação da meta análise}

Nestes artigos foram identificados: tamanho das amostras; variáveis; tipos de medidas de associação; valor da medida de associação; erro padrão; p-value; considerações e limitações; ferramenta utilizada para inferência estatística.

Foram identificados ainda: tamanho das amostras; variáveis; tipos de medidas de associação; valor da medida de associação; erro padrão; $p$-value; considerações e limitações; ferramenta utilizada para inferência estatística.

Outra análise foi em relação aos seguintes fatores críticos de sucesso: cultura de qualidade; seleção de projetos; envolvimento da liderança; alinhamento estratégico; envolvimento dos funcionários, aprendizado e conhecimento.

Cada um dos artigos selecionados pelo método descrito no item anterior foi então analisado individualmente. Foram identificadas as variáveis dependentes e independentes do estudo. Com relação às variáveis independentes, foram isoladas as variáveis referentes aos fatores críticos de sucesso descritos.

Para todas as variáveis, foram identificadas sua escala, o erro padrão e o valor do p-value. Quando o erro padrão não estava disponível, este foi calculado em função do desvio-padrão e do tamanho de amostra, pela fórmula Erro padrão $=\frac{\sigma}{\sqrt{n}}$. No caso do desvio-padrão não estar claramente indicado, o erro padrão foi calculado a partir do $p$-value. Definição de $p$-value: supondo H0 verdadeira, probabilidade de serem encontrados os resultados da amostra; se $p$-value for inferior ao nível de significância pré-estabelecido, realmente é pouco provável que H0 seja verdadeira; logo, a relação encontrada na amostra não foi ao acaso; ela existe, de fato. Definição de nível de significância: probabilidade pré-estabelecida de se rejeitar a 
hipótese nula, sendo esta verdadeira; geralmente, usa-se 0,05; a hipótese nula sempre nega uma significância estatística (por exemplo, relação de dependência entre variáveis). Os valores referentes à contribuição de cada variável identificada nos trabalhos foram tabulados para a realização da meta análise, seguindo o método de Hunter-Schmidt para a meta análise, onde as estatísticas dos testes individuais são convertidas para as variáveis de tamanho de efeito $r$ e $d$, de onde são recalculados por meio das fórmulas do Quadro 8 (HUNTER et al., 1982; HUNTER \& SCHMIDT, 1990).

Para a realização dos cálculos dos resultados acumulados na meta análise, foi utilizada a ferramenta MIX 1.7 (BAX et al. 2006; BAX et al., 2008).

Quadro 8 - Fórmulas para conversão das estatísticas t, F e teste $x^{2}$ para efeito padronizado r.

\begin{tabular}{|c|c|}
\hline $\mathrm{t}$ & $r=\sqrt{\frac{t^{2}}{t^{2}+d f}}$ \\
\hline $\mathrm{F}$ & $r=\sqrt{\frac{F}{F+d f(e)}}$ \\
\hline Two-Way ANOVA & $r=\sqrt{\frac{(F a * d f a)+(F b * d f b)+(F a b * d f a b)+d f(e)}{(F a * d f a)}}$ \\
\hline X2 & $r=\sqrt{\frac{X^{2}}{N}}$ \\
\hline
\end{tabular}

\section{RESULTADOS DA PESQUISA}

Nesta seção estão inseridos os resultados da análise de cada artigo quanto à descrição e a escala dos fatores críticos listados, as variáveis moderadoras adotadas, as variáveis de desempenho medidas. Também foi identificado o método utilizado em cada estudo. Em seguida, todos os artigos selecionados foram organizados em conjunto para a avaliação sistemática dos resultados.

Da análise dos principais artigos e referências do tema Seis Sigma, percebeuse que muitas das obras têm uma visão de implantação e de casos de aplicação do programa, e observando-se a evolução do volume de citações das referências 
através do tempo, é possível notar um forte crescimento da discussão do tema nos últimos 5 anos, conforme pode ser visto na Figura 5.

Figura 5 - Evolução do número de citações às referências de Seis Sigma.

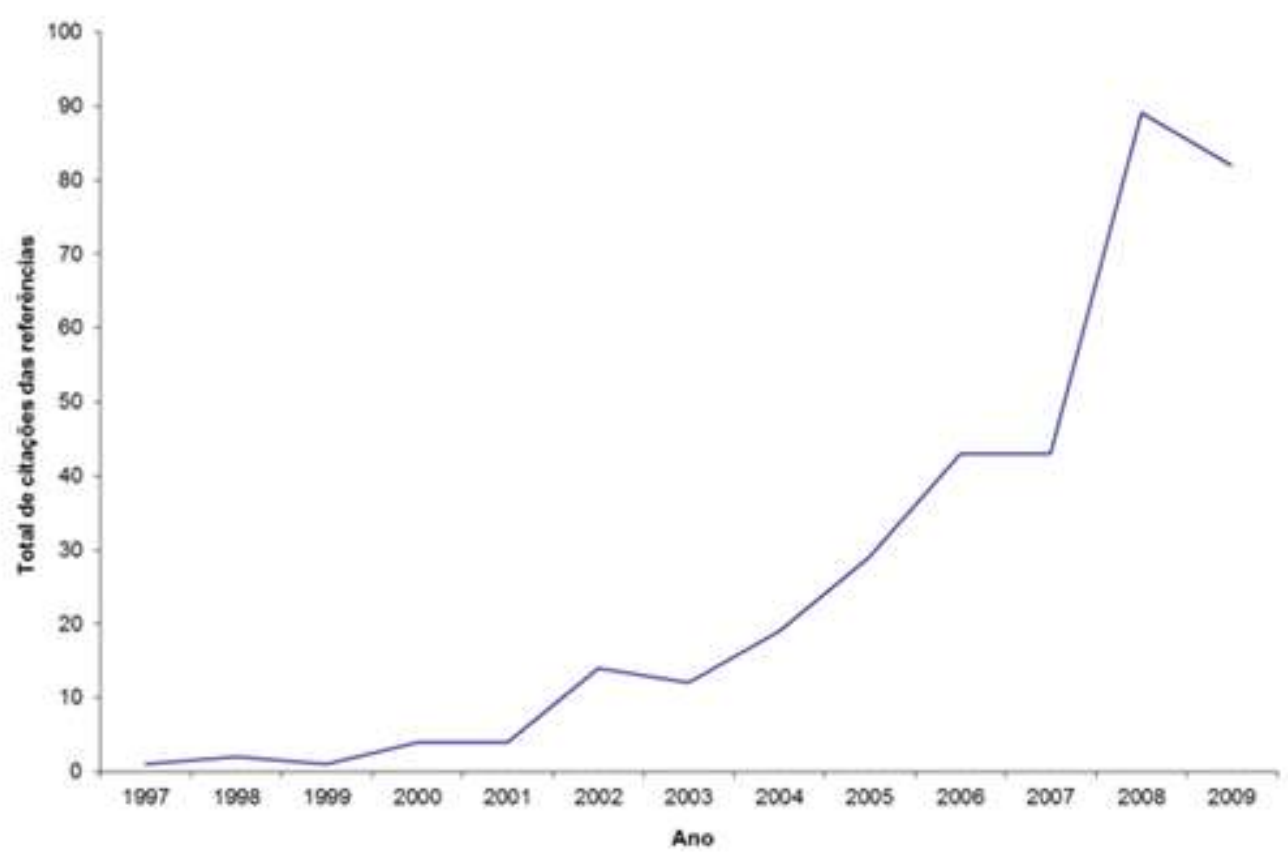

Fonte: Dados extraídos da base de dados ISI Web of Knowledge

4.1 Resultados individuais de cada artigo

Para cada um dos artigos qualificados dentro da metodologia de análise utilizada neste estudo, foi feita uma tabela contendo a síntese dos resultados quantitativos utilizados em cada trabalho para fins de avaliação estatística, de acordo com a Tabela 1. 
Tabela 1- Síntese dos achados das variáveis definidas nos artigos

\begin{tabular}{|c|c|c|c|c|}
\hline Autor & Objetivo do Artigo & Variáveis explanatórias & Escala & Técnica \\
\hline $\begin{array}{l}\text { Kondic et al. } \\
\text { (2009) }\end{array}$ & $\begin{array}{c}\text { Identificar os fatores que } \\
\text { reduzem a aplicação do Seis } \\
\text { Sigma em pequenas empresas }\end{array}$ & $\begin{array}{l}\text { - participação da liderança } \\
\text { - tamanho da organização } \\
\text { - conhecimento }\end{array}$ & ordinal & $\begin{array}{l}\text { Correlação de } \\
\text { Kendall e/ou } \\
\text { Correlação de } \\
\text { Spearman }\end{array}$ \\
\hline $\begin{array}{c}\text { Kumar \& } \\
\text { Antony (2008) }\end{array}$ & $\begin{array}{l}\text { Identificar um padrão histórico de } \\
\text { evolução das iniciativas de seis } \\
\text { sigma como TQM,ISO, Lean, } \\
\text { Seis Sigma e sua relação com } \\
\text { desempenho sobre o universo } \\
\text { de pequenas e médias } \\
\text { empresas no Reino Unido }\end{array}$ & $\begin{array}{l}\text { - envolvimento e comprometimento da liderança } \\
\text { - comunicação } \\
\text { - ligação do seis sigma com o empregado } \\
\text { - ligação do seis sigma com o cliente } \\
\text { - ligação do seis sigma com o negócio } \\
\text { - ligação do seis sigma com os fornecedores }\end{array}$ & ordinal & $\begin{array}{l}\text { Estatística } \\
\text { descritiva }\end{array}$ \\
\hline $\begin{array}{l}\text { Van Iwaarden } \\
\text { et al. (2008) }\end{array}$ & $\begin{array}{c}\text { Identificar a variação de } \\
\text { significado, formas e requistos } \\
\text { de implantação e resultados do } \\
\text { uso do Seis Sigma em três } \\
\text { diferentes países }\end{array}$ & $\begin{array}{l}\text { - resultados positivos dos projetos Seis Sigma } \\
\text { - apoio da liderança } \\
\text { - envolvimento da liderança na seleção dos } \\
\text { projetos } \\
\text { - efetiva e frequente comunicação } \\
\text { - uso das ferramentas aprendidas em ações de } \\
\text { melhoria } \\
\text { - registro dos ganhos financeiros } \\
\text { - asseguramento que as necessidades dos } \\
\text { clientes foram atendidas } \\
\text { - Integração do seis sigma no sistema de gestão } \\
\text { - desempenho positivo do negócio } \\
\text { - aumento da competição no mercado } \\
\text { - aumento das ferramentas e técnicas utilizadas } \\
\text { pelo seis sigma } \\
\text { - pressão do mercado por preço }\end{array}$ & $\begin{array}{l}\text { escala likert } \\
5 \text { pontos }\end{array}$ & Testes $\mathrm{t}$ \\
\hline $\begin{array}{l}\text { Antony et al. } \\
\quad(2008)\end{array}$ & $\begin{array}{l}\text { Aplicação da metodologia Seis } \\
\text { Sigma em empresas de } \\
\text { pequeno e médio porte }\end{array}$ & $\begin{array}{l}\text { - envolvimento e comprometimento da liderança } \\
\text { - comunicação } \\
\text { - ligação do seis sigma com o empregado } \\
\text { - ligação do seis sigma com o cliente } \\
\text { - ligação do seis sigma com o negócio } \\
\text { - ligação do seis sigma com os fornecedores }\end{array}$ & & $\begin{array}{l}\text { Estatística } \\
\text { descritiva }\end{array}$ \\
\hline Cheng (2007) & $\begin{array}{l}\text { Analisar as atividades Seis } \\
\text { Sigma na indústria de Taiwan }\end{array}$ & $\begin{array}{l}\text { - estratégia } \\
\text { - projetos } \\
\text { - treinamento } \\
\text { - clientes }\end{array}$ & razão & ANOVA \\
\hline $\begin{array}{c}\text { Davison \& Al- } \\
\text { Shaghana } \\
(2007)\end{array}$ & $\begin{array}{l}\text { Discutir influências do Seis } \\
\text { Sigma }\end{array}$ & $\begin{array}{l}\text { - demonstração de compromisso com o Seis } \\
\text { Sigma } \\
\text { treinamento, participação dos empregados } \\
\text { - avaliação de desempenho }\end{array}$ & razão & Mann-Whitney \\
\hline
\end{tabular}

\subsection{Resultados do conjunto de artigos avaliado}

A partir do conjunto de artigos, foram encontrados 23 fatores críticos de sucesso para o Seis Sigma, sendo que foi possível identificar 6 variáveis tratadas por mais de um autor, sendo elas cultura de qualidade, seleção de projetos, envolvimento da liderança, alinhamento estratégico, envolvimento dos funcionários 
e aprendizado e conhecimento, conforme pode ser visto nas tabelas Tabela 2 e $\mathrm{O}$ teste de média refere-se ao confronto da média com um valor especificado na hipótese nula e teste de diferença de média refere-se à comparação entre as médias de populações independentes e/ou pareadas.

Tabela 3.

Tabela 2 - Fatores críticos de sucesso encontrados nos artigos e sua contribuição estatística 


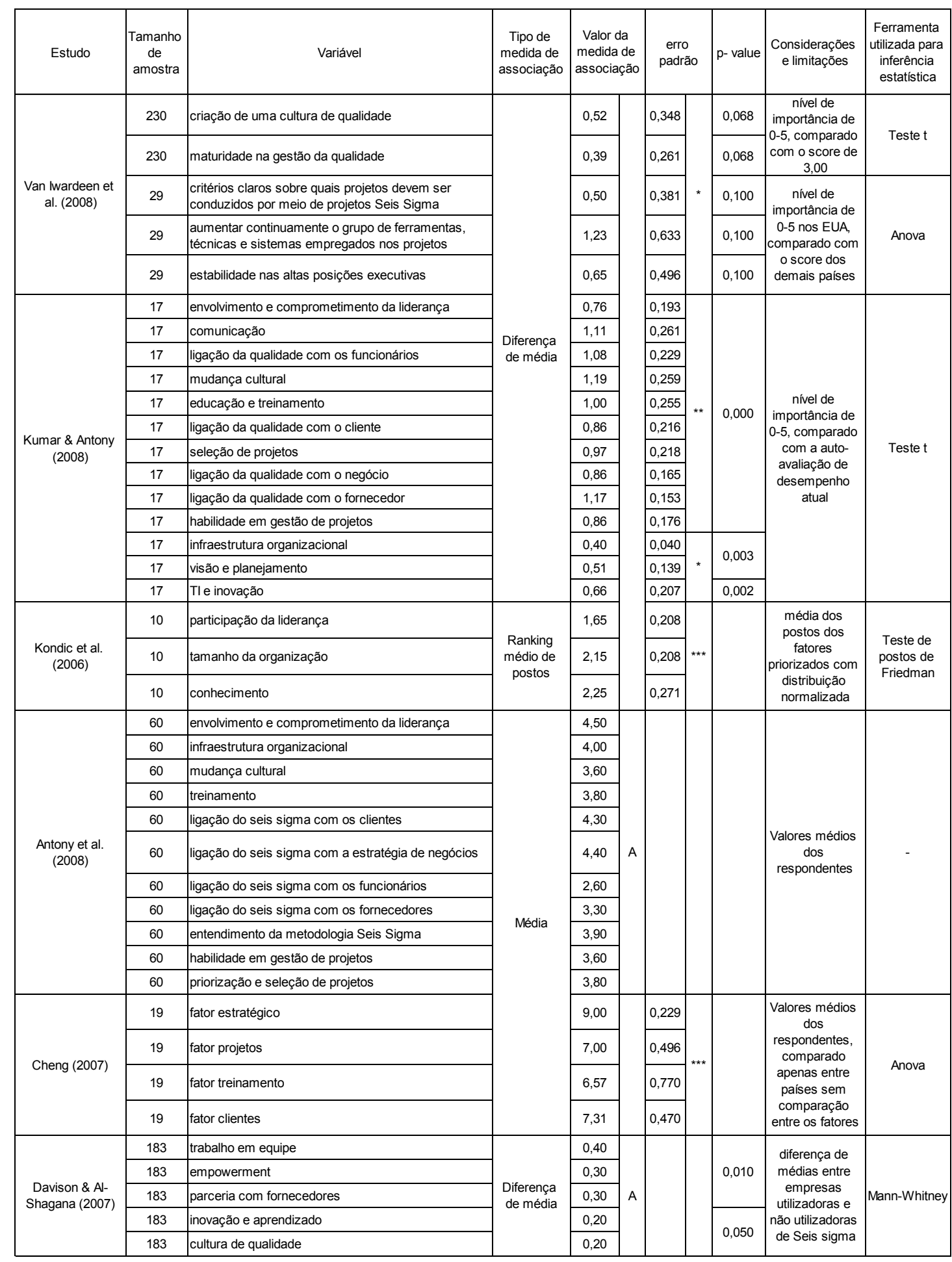

\footnotetext{
A valores estimados a partir de gráficos no artigo

* calculado a partir da diferença encontrada e do nível de significância

** calculado a partir da diferença encontrada e supondo nível de significância de 0,0001

*** calculado a partir do desvio padrão e tamanho de amostra
} 
O teste de média refere-se ao confronto da média com um valor especificado na hipótese nula e teste de diferença de média refere-se à comparação entre as médias de populações independentes e/ou pareadas.

Tabela 3 - Fatores críticos de sucesso encontrados em mais de uma referência.

\begin{tabular}{|c|c|c|c|c|c|c|c|c|c|c|c|c|c|c|c|c|c|c|c|}
\hline \multicolumn{2}{|c|}{$\begin{array}{l}\text { Fator crítico de } \\
\text { sucesso }\end{array}$} & \multicolumn{3}{|c|}{$\begin{array}{l}\text { Cultura de } \\
\text { qualidade }\end{array}$} & \multicolumn{3}{|c|}{$\begin{array}{l}\text { Seleção de } \\
\text { projetos }\end{array}$} & \multicolumn{3}{|c|}{$\begin{array}{c}\text { Envolvimento da } \\
\text { liderança }\end{array}$} & \multicolumn{3}{|c|}{$\begin{array}{l}\text { Alinhamento } \\
\text { estratégico }\end{array}$} & \multicolumn{3}{|c|}{$\begin{array}{c}\text { Envolvimento } \\
\text { dos funcionários }\end{array}$} & \multicolumn{3}{|c|}{$\begin{array}{l}\text { Aprendizado e } \\
\text { conhecimento }\end{array}$} \\
\hline Trabalho & $\mathrm{N}$ & valor & erro & $\begin{array}{c}\mathrm{p}- \\
\text { value }\end{array}$ & valor & erro & $\begin{array}{c}\mathrm{p}- \\
\text { value }\end{array}$ & valor & erro & $\begin{array}{c}\mathrm{p}- \\
\text { value }\end{array}$ & valor & erro & $\begin{array}{c}\mathrm{p}- \\
\text { value }\end{array}$ & valor & erro & $\begin{array}{c}\mathrm{p}- \\
\text { value }\end{array}$ & valor & erro & $\begin{array}{c}\mathrm{p}- \\
\text { value }\end{array}$ \\
\hline $\begin{array}{l}\text { Van Iwardeen et } \\
\text { al. (2008) }\end{array}$ & $\begin{array}{l}230 \\
(29)\end{array}$ & 0,52 & 0,35 & 0,07 & 0,50 & 0,38 & 0,10 & & & & & & & & & & 1,23 & 0,63 & 0,10 \\
\hline $\begin{array}{c}\text { Kumar \& Antony } \\
\quad(2008)\end{array}$ & 17 & 1,19 & 0,26 & 0,00 & 0,97 & 0,22 & 0,00 & 0,76 & 0,19 & 0,00 & 0,86 & 0,17 & 0,00 & 1,08 & 0,23 & 0,00 & 1,00 & 0,25 & 0,00 \\
\hline $\begin{array}{l}\text { Kondic et al. } \\
\qquad(2006)^{*}\end{array}$ & 10 & & & & & & & 1,65 & 0,21 & & & & & & & & 2,25 & $0,27 \mid$ & \\
\hline $\begin{array}{l}\text { Antony et al. } \\
(2008)^{\star *}\end{array}$ & 60 & 3,60 & & & 3,80 & & & 4,50 & & & 4,40 & & & 2,60 & & & 3,80 & & \\
\hline Cheng $(2007)^{\star \star *}$ & 19 & & & & 7,00 & 0,50 & & & & & 9,00 & 0,23 & & & & & 6,57 & 0,77 & \\
\hline $\begin{array}{c}\text { Davison \& Al- } \\
\text { Shagana (2007) }\end{array}$ & 183 & 0,20 & & 0,05 & & & & & & & & & & 0,30 & & 0,01 & 0,20 & & 0,05 \\
\hline
\end{tabular}

* não será considerado devido à métrica se encontrar em postos

** não será considerado por não possui os coeficientes estatísticos para a análise

*** não será considerado por possuir valores em médias puras e não efeito de diferença de médias

Para os fatores cultura da qualidade, seleção de projetos, envolvimento dos funcionários e aprendizado e conhecimento, há mais de um estudo que utiliza o mesmo valor estatístico (diferença de médias) para sua avaliação.

Procedendo a meta análise para esses fatores, obtivemos os resultados tabulados nas tabelas 4,5 e 6 .

Tabela 4 - Resultados das entradas do estudo de meta-análise 

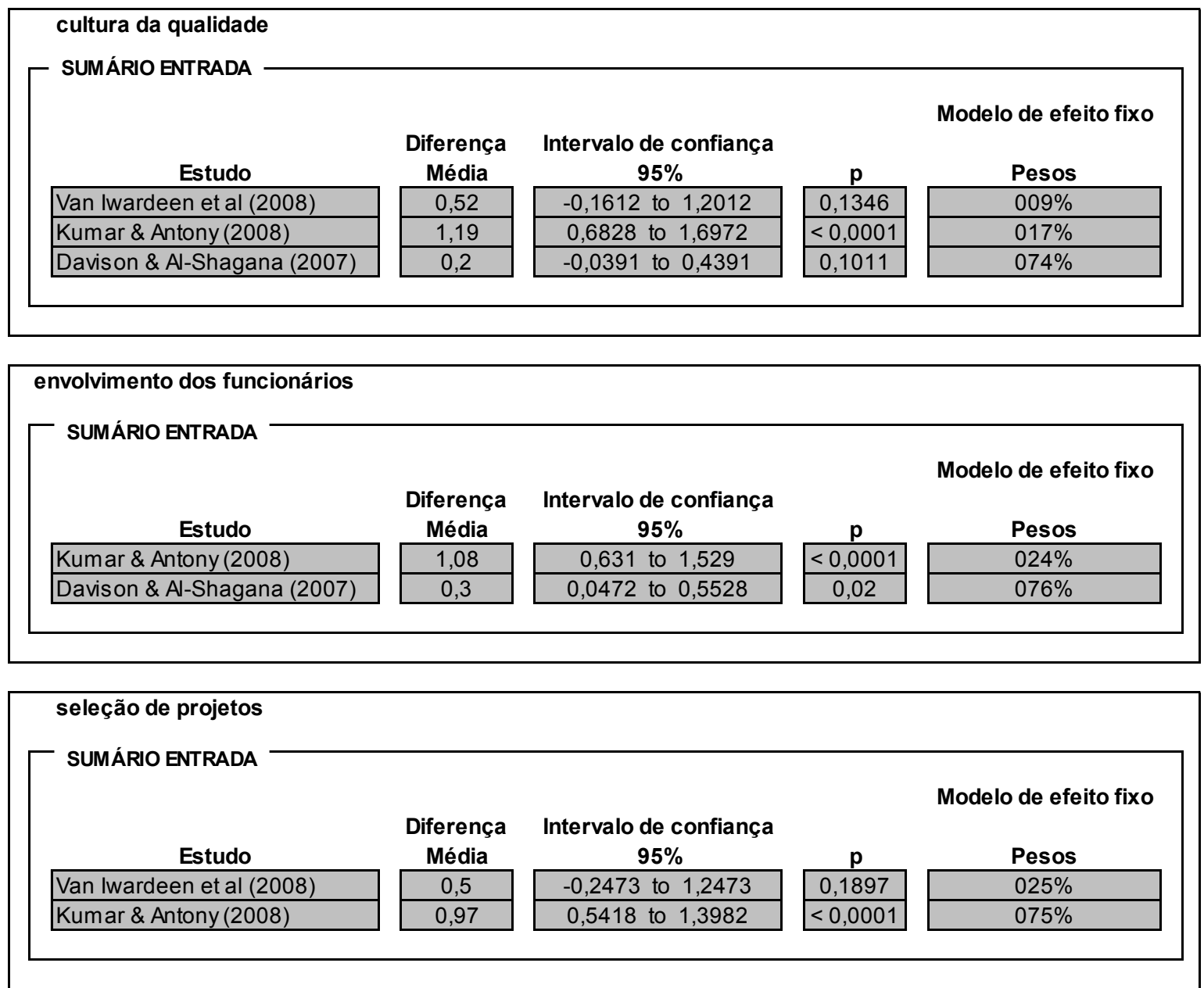

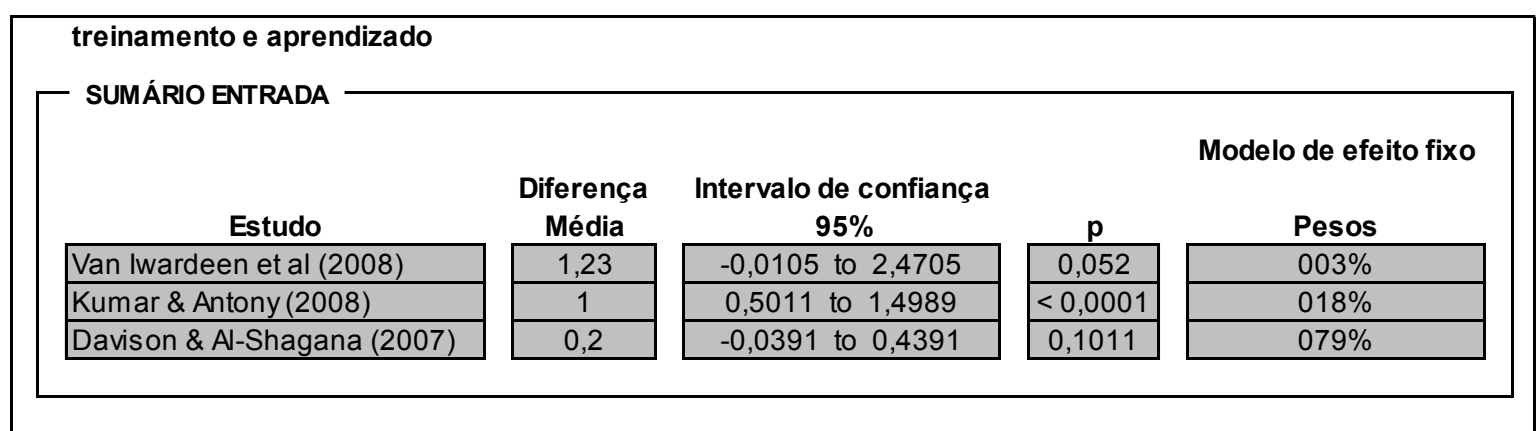

Tabela 5 - Resultados da meta análise dos fatores selecionados

Revista Produção Online, Florianópolis, SC, v.14, n. 2, p. 465-498, abr./jun. 2014. 

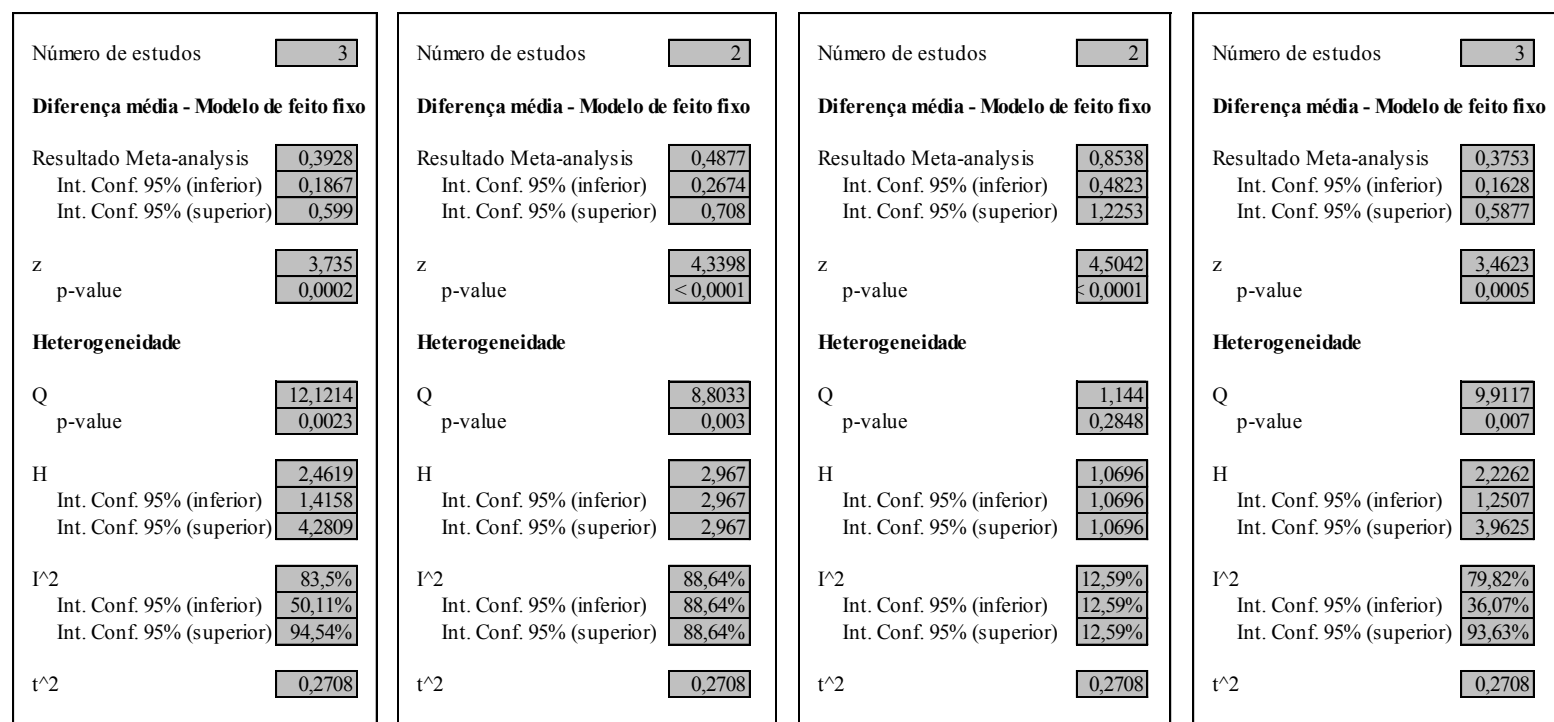

Tabela 6 - Resultados acumulados da meta análise

\begin{tabular}{|c|c|c|c|c|c|}
\hline Estudo & $\begin{array}{c}\text { Diferença } \\
\text { Média Acumulada }\end{array}$ & $\begin{array}{l}\text { Modelo de efe } \\
\text { Intervalo de confiança } \\
95 \% \\
\end{array}$ & xo & $\mathbf{p}$ & n̊ de estudos \\
\hline Van Iwardeen et al (2008) & 0,52 & $-0,1612$ to 1,2012 & 1,4961 & 0,1346 & 1 \\
\hline Above \& Kumar \& Antony (2008) & 0,951 & 0,5442 to 1,3579 & 4,5819 & $<0,0001$ & 2 \\
\hline Meta-analysis outcome & 0,3928 & 0,1867 to 0,599 & 3,735 & 0,0002 & 3 \\
\hline
\end{tabular}

\begin{tabular}{|c|c|c|c|c|c|}
\hline \multirow[b]{2}{*}{ Estudo } & \multicolumn{4}{|c|}{ Modelo de efeito fixo } & \multirow[b]{2}{*}{ n̊ de estudos } \\
\hline & $\begin{array}{c}\text { Diferença } \\
\text { Média Acumulada }\end{array}$ & $\begin{array}{c}\text { Intervalo de confiança } \\
95 \%\end{array}$ & $\mathbf{z}$ & p & \\
\hline Kumar \& Antony (2008) & 1,08 & 0,631 to 1,529 & 4,7144 & $<0,0001$ & 1 \\
\hline Meta-analys is outcome & 0,4877 & 0,2674 to 0,708 & 4,3398 & $<0,0001$ & 2 \\
\hline
\end{tabular}

\begin{tabular}{|c|c|c|c|c|c|}
\hline \multirow[b]{2}{*}{ Estudo } & \multicolumn{4}{|c|}{ Modelo de efeito fixo } & \multirow[b]{2}{*}{ n̊ de estudos } \\
\hline & $\begin{array}{c}\text { Diferença } \\
\text { Média Acumulada }\end{array}$ & $\begin{array}{c}\text { Intervalo de confiança } \\
95 \%\end{array}$ & $\mathbf{z}$ & p & \\
\hline Van Iwardeen et al (2008) & 0,5 & $-0,2473$ to 1,2473 & 1,3114 & 0,1897 & 1 \\
\hline Meta-analysis outcome & 0,8538 & 0,4823 to 1,2253 & 4,5042 & $<0,0001$ & 2 \\
\hline
\end{tabular}

\begin{tabular}{|c|c|c|c|c|c|}
\hline \multicolumn{6}{|c|}{ Modelo de efeito fixo } \\
\hline Es tudo & $\begin{array}{c}\text { Diferença } \\
\text { Média Acumulada }\end{array}$ & $\begin{array}{c}\text { Intervalo de confiança } \\
95 \%\end{array}$ & $\mathbf{z}$ & $\mathbf{p}$ & n̊ de estudos \\
\hline Van Iwardeen et al (2008) & 1,23 & $-0,0105$ to 2,4705 & 1,9434 & 0,052 & 1 \\
\hline Above \& Kumar \& Antony (2008) & 1,032 & 0,5692 to 1,4949 & 4,3701 & $<0,0001$ & 2 \\
\hline Meta-analysis outcome & 0,3753 & 0,1628 to 0,5877 & 3,4623 & 0,0005 & 3 \\
\hline
\end{tabular}

\section{DISCUSSÃO DOS RESULTADOS}

Revista Produção Online, Florianópolis, SC, v.14, n. 2, p. 465-498, abr./jun. 2014. 


\subsection{Análise das técnicas estatísticas utilizadas}

Do ponto de vista do arcabouço teórico que respalda a análise estatística de resultados de pesquisas quantitativas, é possível perceber a subutilização das técnicas estatísticas multivariadas.

O estudo de Cheng (2007), por exemplo, ao possuir variáveis dependentes e independentes do tipo quantitativa (no caso, ordinal), seria elegível para o uso da técnica de correlação canônica. Estudos como o de Davison \& Al-Shagana (2007) e Kumar \& Antony (2008), ao comparar o comportamento de variáveis independentes quantitativas (ordinais) em categorias binomiais, poderiam utilizar-se da técnica de regressão logística.

Já o estudo de Van Iwardeen et al. (2008), embora tenha o mesmo tipo de variáveis de Davison \& Al-Shagana (2007) e Kumar \& Antony (2008), possui variável independente de múltiplos níveis, o que levaria a indicação de uso da técnica de análise discriminante.

O estudo de Kondic et al. (2009), busca identificar a repulsa de gestores da qualidade por características típicas de insucesso, o que poderia ser melhor explorado em uma análise conjunta (conjoint analysis).

O trabalho de Antony et al. (2008) sequer realiza algum tipo de inferência estatística, seja uni ou multivariada, indicando que os dados poderiam ser melhor explorados. Mesmo na estatística descritiva, foram representados somente dados de média, insuficientes para uma análise mais profunda. Davison \& Al-Shagana (2007) realizam uma análise estatística e demonstram o $p$-value, no entanto não apresentam os valores da diferença ou das médias, sendo necessário inferir estes dados por meio dos gráficos.

Nota-se também que do ponto de vista estatístico, em todos os trabalhos a representação dos resultados levantados foi excessivamente resumida, levando a que dados importantes como desvio-padrão, erro-padrão, valores de estatísticas $t, z$, $\mathrm{F}, p$-value e intervalos de confiança não fossem representados dentro dos artigos, diminuindo a capacidade do leitor de entender os reais impactos das diferenças encontradas. 
Também chama a atenção o fato de que dos 6 artigos analisados, 3 possuem tamanho de amostra inferior a 20 casos. Considerando-se o fato de todos os artigos possuírem pelo menos 4 variáveis independentes, a amostra por variável utilizada fica abaixo do recomendável para todos os testes, reduzindo o poder das avaliações e levando a um aumento do erro tipo II.

Além disso, nenhum dos artigos menciona se houve ou não análise quanto a pré-requisitos das técnicas, tais como normalidade e variâncias iguais nos grupos.

\subsection{Análise dos resultados dos Fatores Críticos de Sucesso do Seis Sigma}

A maioria dos autores recorre à literatura corporativa relacionada ao Seis Sigma ou à literatura tradicional de TQM na construção dos fatores críticos de sucesso do Seis Sigma. A partir do cruzamento destas fontes, seis fatores críticos emergem de forma recorrente nos trabalhos, sendo eles cultura de qualidade, seleção de projetos, envolvimento da liderança, alinhamento estratégico, envolvimento dos funcionários e aprendizado e conhecimento.

Analisando de forma gráfica, na Tabela 6 é possível notar que a importância do fator seleção de projetos demonstra promover uma diferença entre médias superior a das demais variáveis.

É possível notar que todos os intervalos de confiança dos fatores estudados melhoraram quando analisados em conjunto, quando comparados aos fatores isoladamente. Este efeito se dá devido à redução dos erros devido ao tamanho de amostra, que é um fator limitante de vários dos artigos estudados.

Os quatro fatores estudados mostraram-se significativos com $\alpha=5 \%$, o que reforça que de fato todos os artigos estudados estavam corretos em indicá-los como fatores críticos para o sucesso do Seis Sigma. No entanto, os demais fatores não puderam ser comparados, então não é possível realizar a análise comparativa em relação a estes fatores.

Do ponto de vista prático, esta conclusão mostra as semelhanças entre o Seis Sigma e as iniciativas de qualidade, dado que há fatores significativos em seu sucesso que também já foram demonstrados na literatura como fatores críticos de sucesso de iniciativas de qualidade. 
No entanto, surge de forma clara e preponderante um fator crítico de sucesso que não pertence ao universo tradicional da qualidade, que é a seleção de projetos.

Uma característica importante do Seis Sigma, que o relaciona com a área de Gestão de Projetos, é o fato de que uma das características importantes da iniciativa é sua atuação projetizada. Zu et al. (2008) comprovam que o núcleo de atividades que diferencia outras iniciativas de Qualidade do Seis Sigma é seu procedimento estruturado de melhoria, que é caracterizado pela condução disciplinada e padronizada da realização planejada de atividades de melhoria por meio de projetos. Linderman et al. (2003), exploram a característica projetizada do Seis Sigma e suas metas específicas para propor um desempenho diferenciado do Seis Sigma frente a outras iniciativas de melhoria. Snee (2001, p. 66) propõe uma definição de projetos Seis Sigma como "um problema agendado para solução que tem um conjunto de indicadores que podem ser usados para selecionar os objetivos e metas do projeto e monitorar o progresso".

Observando-se o tema de alinhamento estratégico dos projetos Seis Sigma, muita atenção tem sido dada ao tema de seleção de projetos, que é um tema chave dentro da Gestão de Portfólio. Gonçalves \& Musetti (2008) verificam em seu estudo que a estruturação e sistematização do processo de seleção de projetos Seis Sigma está diretamente relacionado aos resultados obtidos nestes projetos.

Muitos dos trabalhos acadêmicos que relacionam Seis Sigma à Gestão de Portfólio de Projetos tratam de métodos para seleção de projetos Seis Sigma, partindo-se desta necessidade de que tal seleção reflita necessidades estratégicas da organização.

Gijo \& Rao (2005) discutem as dificuldades e obstáculos na implementação do programa Seis Sigma, enumerando entre elas a questão da seleção de projetos, seu alinhamento com a estratégia e a participação da liderança.

Kharaman \& Büyüközkan (2008) apresentam um método de seleção de projetos que contempla múltiplos objetivos, considerando maximização de benefícios financeiros; capacidade de processos; satisfação de clientes e minimizando tempo de ciclo dos projetos; risco e custos, utilizando AHP e lógica fuzzy. Su \& Chou (2008) também propõem o AHP como forma para que a alta liderança da empresa possa opinar e selecionar os temas dos projetos, e o FMEA é proposto como ferramenta de 
análise de risco na seleção dos projetos. Büyüközkan \& Öztürkcan (2010) propõem um método baseado em processo analítico de redes (Analytic Network Process ANP) desenvolvido pelo Decision Making Trial and Evaluation Laboratory (DEMATEL).

Yang \& Hsieh (2009) propõem o método Delphi fuzzy multicritérios para a avaliação dos projetos, considerando além das necessidades colocadas pelos gestores e do impacto financeiros dos projetos, incorporando os critérios de prêmios e certificações de qualidade como ponderação da seleção dos projetos.

Em todos esses casos, verifica-se uma preocupação dos autores em contemplar mais de um critério na seleção dos projetos Seis Sigma e também de promover a participação da alta liderança no processo decisório.

Nestes artigos, é possível identificar uma preocupação com os processos de seleção de projetos, que pode ser notado pelo uso de palavras como Analytic Network Process, Delphy Method, Fuzzy Analytic Hierarchy Process, Extent Analysis Method. Também é possível notar uma preocupação com a flexibilidade dos modelos propostos, notável no uso das palavras Multi-objective, Decision Making, Multiple Criteria Decision Making, AHP, Hybrid Method. Além disso, há uma preocupação com criação de sistemas, modelos ou programas estruturados para a seleção de projetos, como se pode notar do uso das expressões System, Model, Programming, Methodology.

Outro vertente presente na análise das palavras-chaves é a preocupação com os distintos níveis de capacitação e dedicação dos líderes de projetos, revelado nas expressões Master Black Belt, Black Belt e Green Belt.

Com isso, percebe-se que já existe uma preocupação acadêmica com a seleção de projetos Seis Sigma e são propostos modelos para esta etapa da implementação e esta preocupação possui fundamento, já que a seleção de projetos revelou-se um fator crítico importante no sucesso do Seis Sigma.

\section{CONCLUSÕES}


Do trabalho realizado, é possível concluir que alguns autores têm tratado de explorar os fatores críticos de sucesso do Seis Sigma, baseados na literatura corporativa e nos fundamentos de qualidade que embasam o Seis Sigma. Poucos estudos quantitativos foram realizados e um número muito extenso de variáveis foi utilizado. Devido às limitações de tamanho de amostra, nem todos os fatores puderam ser explorados a contento.

Do ponto de vista estatístico, as principais limitações estatísticas são de tamanho de amostra e de escolhas de ferramentas adequadas. Considerando a apresentação dos dados, a apresentação incompleta dos dados dos estudos foi um obstáculo importante ao estudo de validade estatística.

Numa abordagem relacionada ao tema, identificam-se seis fatores comuns. Destes, quatro puderam ser comparados: cultura da qualidade, envolvimento dos funcionários, seleção de projetos e treinamento e aprendizado. De todos os fatores, a meta análise demonstrou que todos são estatisticamente significativos no conjunto dos estudos e que o que produz a maior diferença entre médias é a seleção de projetos, mostrando que um dos diferenciais entre o Seis Sigma e as iniciativas de qualidade é sua integração com a Gestão de Portfólio de Projetos.

Uma limitação deste estudo é a utilização de estimativas para o cálculo do erro-padrão. Outra limitação é a dificuldade de tratar dados medidos em escalas e unidades distintas, o que reduziu o número de estudos que pôde ser incluído em cada meta análise realizada.

\section{AGRADECIMENTOS}

Agradecemos aos avaliadores do trabalho, que muito contribuíram para a pesquisa com os seus comentários e sugestões. Agradecemos também à CAPES e ao CNPq o suporte ao projeto de pesquisa.

\section{REFERÊNCIAS}


ANTONY, J. BAÑUELAS, R. Key ingredients for the effective implementation of six sigma program. Measuring Business Excellence. v. 6, n. 4, p. 20-27, 2002. http://dx.doi.org/10.1108/13683040210451679

ANTONY, J. KUMART, M.; LABIB, A. Gearing Six Sigma into UK manufacturing SMEs: Results from a pilot study. Journal of the Operational Research Society. $v$. 59, n. 4, p. 482-493, 2008. http://dx.doi.org/10.1057/palgrave.jors.2602437

ATALLAH, A.N.; CASTRO, A.A. Revisão sistemática e meta análise. In: ATALLAH, A.N.; CASTRO A.A. Evidências para melhores decisões clínicas. São Paulo: Lemos-Editorial; 1998. Disponível em:

<http://www.epm.br/cochrane/bestevidence.htm>.

BAX, L. et al. Development and validation of MIX: comprehensive free software for meta-analysis of causal research data. BMC Medical Research Methodology, v. 6, n. 50, 2006.

BAX, L. et al. MIX: comprehensive free software for meta-analysis of causal research data. Version 1.7. http://mix-for-meta-analysis.info, 2008.

BREYFOGLE, F. W. Implementing six sigma: smarter solutions using statistical methods, John Wiley \& Sons, 1999.

CARVALHO, M.M.; LEE HO, L.; PINTO, S.H.B. Implementação e difusão do programa seis sigma no Brasil. Revista Produção, v. 17, n. 3, p. 486-501, 2007. http://dx.doi.org/10.1590/S0103-65132007000300007

CHENG, J. Comparative study of local and transnational enterprises in taiwan and their implementation of six sigma. Total Quality Management, v. 18, n. 7, p. 793806, 2007. http://dx.doi.org/10.1080/14783360701349864

CHENG, J.L. Six sigma and tqm in taiwan: an empirical study of discriminate analysis. Total Quality Management \& Business Excellence, v. 20, n. 3, p. 311326, 2009. http://dx.doi.org/10.1080/14783360902719675

CORONADO, R. B.; ANTONY, J. Critical success factors for the successful implementation of six sigma. The TQM Magazine, v. 14, n. 2, p. 92-99, 2002 http://dx.doi.org/10.1108/09544780210416702

DAVISON, L.; AL-SHAGHANA, K. The link between six sigma and quality culture an empirical study. Total Quality Management, v. 18, n. 3, p. 249-265, 2007. http://dx.doi.org/10.1080/14783360601152269

EL-HAIK, B.; ROY, D.M. Service design for six sigma - a roadmap for excellence. John Wiley \& Sons, 2005. http://dx.doi.org/10.1002/0471744719 
FILIPPINI, R. Operations management research: some reflections on evolution, models and empirical studies in OM. International Journal, v.17, n. 7, p. 655-670, 1997.

FORZA, C. Survey research in operations management: a process-based perspective. International Journal of Operations \& Production Management, v. 22, n. 2, p. 152-194, 2002. http://dx.doi.org/10.1108/01443570210414310

GIJO, E.V.; RAO, T.S. Six sigma implementation - hurdles and more hurdles. Total Quality Management \& Business Excellence, v.16, n. 6, p. 721-725, 2005. http://dx.doi.org/10.1080/14783360500077542

GOH, T.N. A strategic assessment of six sigma. Quality and Reliability Engineering International, v. 18, n. 5, p. 403-410, 2002. http://dx.doi.org/10.1002/are.491

GONÇALVEZ, B.S.O.; MUSETTI, M. A. A importância do processo de alinhamento da estratégia com projetos Seis Sigma: um estudo multi-casos em operadores logísticos. Gestão \& Produção, v. 15, p. 551-562, 2008.

http://dx.doi.org/10.1590/S0104-530X2008000300010

GOUVEAA, M.A. Modelos multivariados aplicados à administração II. Material de aula, 2010.

HACKMAN, J. R., WAGEMAN, R. Total quality management: empirical, conceptual, and practical issues. Administrative Science Quarterly, v. 40, p. 309-342, 1995. http://dx.doi.org/10.2307/2393640

HAHN, G.J.; HILL, W.I.; HOERL, R.W.; ZINKGRAF, S.A. The impact $f$ six sigma improvement - a glimpse into the future of statistics. The American Statistician, v.53; n. 3, p. 208-215, 1999.

http://dx.doi.org/10.2307/2686099

http://dx.doi.org/10.1080/00031305.1999.10474462

HAIR, Jr. et al. Análise multivariada de dados. Porto Alegre: Bookman, 2009.

HAIR, Jr. et al. Multivariate data analysis with readings. Prentice-Hall, Englewood Cliffs, NJ, 1995.

HARRY, M.; Linsenmann, D. The six sigma fieldbook. New York: Currency Doubleday, 2006.

HARRY, M.; SCHROEDER, R. Six sigma: the new breakthrough management strategy revolutionizing the world's top corporation. New York: Currency Doubleday, 2000. 
HENDERSON, K., EVANS, J. Successful implementation of six sigma: benchmarking General Electric Company. Benchmarking and International Journal, v. 7, n. 4, p. 260-281, 2000. http://dx.doi.org/10.1108/14635770010378909

HOERL, R.W. Six sigma and the future of the quality profession. Quality Progress. v.31, n. 6, p. 35-42, 1998.

HOERL, R. Six sigma black belts: what do they need to know? Journal of Quality Technology, v. 33, n. 4, p. 391-406, 2001.

HUNTER, J.; SCHMIDIT, F. A methods of meta-analysis: correcting error and bias in research findings. Beverly Hills: Sage, 1990.

HUNTER, J.; SCHMIDIT, F.; JACKSON, G. Meta-analysis: cumulating research findings across studies. Beverly Hills: Sage, 1982.

KAHRAMAN, C.; BUYUKOZKAN, G. A Combined fuzzy ahp and fuzzy goal programming approach for effective six-sigma project selection. Journal of MultipleValued Logic and Soft Computing, v. 14, n. 6, 2008.

KAYNACK, $\mathrm{H}$. The relationship between total quality management practices and their effects on firm performance. Journal of Operations Management, v. 21, n. 4, p. 405-435, 2003. http://dx.doi.org/10.1016/S0272-6963(03)00004-4

KONDIC, Z.; MAGLIC, L.; SAMERDZIC, I. Analysis and ranking of factors impacting application of the 6 sigma: methodology in small production organizations using the prior factor ranking method. Tehnicki Vjesnik-Technical Gazette, v.16, n. 2, p. 1725, 2009.

KUMAR, M.; ANTONY, J. Comparing the quality management practices in UK SMEs. Industrial Management \& Data Systems, v.108, n. 9, p. 1153-1166, 2008. http://dx.doi.org/10.1108/02635570810914865

KWAK, Y.H.; ANBARI, F.T. Benefits, obstacles, and future of six sigma approach. Technovation, v. 26, p. 708-715, 2006.

http://dx.doi.org/10.1016/j.technovation.2004.10.003

LINDERMAN, K. Six sigma: a goal-theoretic perspective. Journal of Operations Management, v. 21, n., 2, p.193-203, 2003.

MARTINS, G. A.; THEÓPHILO, C. R. Metodologia da investigação científica para ciências sociais aplicadas. São Paulo: Atlas, 2007.

PANDE, P. S.; NEUMAN, R. P.; CAVANAGH, R. R. Estratégia seis sigma: como a GE, a Motorola e outras grandes empresas estão aguçando seu desempenho. Rio de Janeiro: Qualitymark, 2000. 
PANDE, P. S.; NEUMAN, R. P.; CAVANAGH, R. R. Estratégia seis sigma. Rio de Janeiro: Qualitymark, 2001.

PYZDEK, T. Uma ferramenta em busca do defeito zero. HSM Management, v. 38, p. 63-70, 2003.

RAISINGHANI, M.S. Six Sigma: concepts, tools, and applications. Industrial Management \& Data Systems. v. 105, n. 3-4, p. 491-505, 2005.

http://dx.doi.org/10.1108/02635570510592389

ROTONDARO, Roberto G. Seis sigmas: estratégia gerencial para a melhoria de processos, produtos e serviços. São Paulo: Atlas, 2002.

Schroeder, R.G.Six sigma: definition and underlying theory. Journal of Operations Management, v. 26, n. 4, p. 536-554, 2007.

http://dx.doi.org/10.1016/j.jom.2007.06.007

SNEE, R.D.; RODEBAUGH JR. The project selection process. Quality Progress. p. 78-80, 2002.

SU, C.; CHOU, C. A systematic methodology for the creation of Six Sigma projects: a case study of semiconductor foundry. Expert Systems with Applications, v. 34, p. 2693-2703, 2008. http://dx.doi.org/10.1016/j.eswa.2007.05.014

TABACHNICK, B.G.; FIDELL, L.S. Using multivariate statistics. Allyn \& Bacon, 1996.

SNEE, R. D. Dealing with the achilles heel of six sigma initiatives. Quality Progress. v. 34, n. 3, p.66, 2001.

TABACHNICK, B.G.; FIDELL, L. Using multivariate statistics, 1996.

VAN IWAARDEN, J. The six sigma improvement approach: a transnational comparison. International Journal of Production Research, v. 46, n. 23, p. 67396759, 2008. http://dx.doi.org/10.1080/00207540802234050

YANG, K. Design for six sigma and value creation. Manufacturing Engineering. v.1, n. 4, p. 355-368, 2005.

YANG, T. HSIEH, C. Six-Sigma project selection using national quality award criteria and Delphi fuzzy multiple criteria decision-making method, expert Systems with Applications. An International Journal, v. 36, n. 4, p. 7594-7603, 2009.

YEUNG, A.C.L.; CHENG, T.C.E.; LAI, K. An operational and institutional perspective on total quality management. Production and Operations Management. v. 15, n. 1, p. 156-170, 2006. 
ZU, X.; FREDENDALL, L.D.; DOUGLAS, T.J. The evolving theory of quality management: the role of Six Sigma. Journal of Operations Management, v. 26, n. 5, p. 630-650, 2008. http://dx.doi.org/10.1016/j.jom.2008.02.001

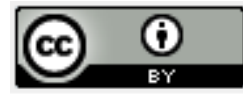

Artigo recebido em 18/06/2012 e aceito para publicação em 31/03/2014.

DOI: http://dx.doi.org/10.14488/1676-1901.v14i2.1348 